\title{
Differential regulation of neuropeptide $Y$ in the amygdala and prefrontal cortex during recovery from chronic variable stress
}

\author{
Jennifer L. McGuire ${ }^{1}$, Lauren E. Larke ${ }^{2,3}$, Floyd R. Sallee ${ }^{3}$, James P. Herman ${ }^{2,3}$ and Renu Sah ${ }^{2,3}$ \\ ${ }^{1}$ Center for Neuroscience and Regenerative Medicine, Department of Psychiatry, Uniformed Services University, Bethesda, MD, USA \\ ${ }^{2}$ Neuroscience Graduate Program, University of Cincinnati, Cincinnati, OH, USA \\ ${ }^{3}$ Department of Psychiatry, University of Cincinnati, Cincinnati, OH, USA
}

\section{Edited by:}

Luke R. Johnson, Uniformed Services University of the Health Sciences, USA

\section{Reviewed by:}

Phillip R. Zoladz, Ohio Northern

University, USA

Amanda Sharko, University of South

Carolina School of Medicine, USA

${ }^{*}$ Correspondence:

Jennifer L. McGuire, Department of Psychiatry, Uniformed Services University, 4301 Jones Bridge Road, Bethesda, MD 20814, USA.

e-mail: jennifer.mcguire.ctr@usuhs.mil
Accumulating evidence from clinical studies and pre-clinical animal models supports a role for neuropeptide $Y$ (NPY) in adaptive emotional response following stress. The long-term impact of stress, particularly chronic stress, on availability, and function of resilience factors such as NPY may be critical to understanding the etiology of stress-related psychopathology. In these studies, we examined expression of NPY during recovery from a chronic variable stress (CVS) model of repetitive trauma in rats. Due to the importance of amygdala and prefrontal cortex in regulating emotional responses, we predicted chronic changes in NPY expression could contribute to persistent behavioral deficits seen in this model. Consistent with the hypothesis, ELISA for NPY peptide identified a significant reduction in NPY at the delayed (7 days) recovery time-point. Interestingly, a significant increase in prefrontal NPY was observed at the same recovery time-point. The mRNA expression for NPY was not changed in the amygdala or PFC, although there was a modest but not statistically significant increase in NPY mRNA at the delayed recovery time-point in the prefrontal cortex. The observed changes in NPY expression are consistent with maladaptive coping and enhanced emotionality, due to the nature of NPY signaling within these respective regions, and the nature of reciprocal connections between amygdala and prefrontal cortex.

Keywords: neuropeptide $Y$, amygdala, resilience, prefrontal cortex, chronic variable stress

\section{INTRODUCTION}

Accumulating evidence from pre-clinical and clinical studies implicates neuropeptide $\mathrm{Y}(\mathrm{NPY})$ as an important stress resiliency factor/hormone. NPY acts directly in limbic forebrain structures, antagonizing the actions of pro-anxiety hormone, corticotropinreleasing hormone (CRH) (Heilig, 2004; Giesbrecht et al., 2010) working to maintain balance between pro- and anti-anxiety signaling and helping to regulate emotional state (Sajdyk et al., 2004). Additionally, NPY in the amygdala regulates the expression of fear responses (Fendt and Fanselow, 1999). Animals over-expressing NPY in forebrain regions (Thorsell et al., 2000) or exclusively in the amygdala (Primeaux et al., 2005) are resistant to anxiogenic stress as measured in pharmacologically validated behavioral tests of rodent anxiety. Recent studies in humans corroborate the data from animal studies. A variant allele in the promoter region of NPY is linked to higher trait anxiety (Zhou et al., 2008), and increased psychopathology after adversity in analyses of gene $x$ environment interaction (Sommer et al., 2010). Interestingly, lower haplotypedriven NPY expression predicted higher emotion-induced activation of the amygdala, as wells as higher neuroticism scores and diminished resiliency (Zhou et al., 2008). Reduced concentrations of NPY are observed in cerebrospinal fluid of posttraumatic stress disorder (PTSD) patients (Sah et al., 2009) and in plasma of trauma exposed individuals (Morgan III et al., 2003). Increased plasma NPY levels are correlated with symptom improvement in individuals with past PTSD, supporting an association of NPY with coping and resilience (Yehuda et al., 2006). Collectively, a considerable body of evidence supports the relevance of NPY as an important regulator of stress and fear responses.

Stress-associated psychopathologies are often associated with inadequate stress coping and failure to recover from traumatic life events. Optimal function of putative resiliency factors such as NPY may be essential for adequate reactivity to and recovery from stress. In this regard, it is important to investigate how stress impacts long-term expression of NPY. This is particularly relevant for repeated stress exposure, where depletion of stress buffering systems are likely.

In this report we investigated regulation of NPY expression after cessation of chronic stress, where factors influencing resilience would be most critical for recovery. We used a chronic variable stress (CVS) paradigm recently developed by our group as a model of chronic traumatization and posttraumatic-like phenomena (McGuire et al., 2010). Exposure to CVS produces a delayed expression of enhanced fear reinstatement and fearful arousal, behaviors that may be impacted by a dysregulation in NPY. To test the hypothesis that repeated stress would dysregulate neural NPY systems, NPY mRNA, and peptide expression were measured at early and delayed recovery time-points in the amygdala and prefrontal cortex, brain regions implicated in posttraumatic pathophysiology (Shin et al., 2006; Liberzon and Sripada, 2008). 
In support of our hypothesis, central NPY systems manifest alterations in mRNA and protein expression during recovery from CVS in both amygdala (down-regulation) and PFC (up-regulation), both of which are consistent with exaggerated stress responsiveness observed in this model.

\section{MATERIALS AND METHODS THE CVS MODEL}

Subjects were male Long-Evans rats between 225 and $250 \mathrm{~g}$ (Harlan, Indianapolis, IN, USA). Animals were housed in a climatecontrolled vivarium on a 12:12 light dark cycle, lights on 6:00 a.m. All procedures were reviewed and approved by the University of Cincinnati animal care and use committee.

The CVS model was as previously described (McGuire et al., 2010). Subjects were randomly assigned to weight matched control and chronic stress groups. Briefly, experimental animals underwent two stressors a day, morning, and afternoon, for 7 days. Morning and afternoon stressors were administered between 0900-1100 and 1400-1600 hours, respectively. Stressors were selected to include both primarily anxiogenic and primarily physiologic stressors, including restraint, hypoxia, forced swimming, cold, temporary crowding, and agitation of the cages. In addition to the daily stressors, twice during the CVS period the animals were housed overnight in a confined space (a mouse shoebox cage). Overnight stressors began immediately after cessation of afternoon stressors and terminated at the initiation of the next day's morning stressor. Within the CVS and control groups, animals were further subdivided in early and delayed recovery time-points and sacrificed at either $24 \mathrm{~h}$ (early) or 7 days (delayed) after termination of CVS. Brains were rapidly isolated: a midline sagittal incision was made to divide the brain into two equal halves that were then rapidly flash frozen in isopentane on dry ice. One half was processed for NPY ELISA for peptide concentrations while the other was subjected to in situ hybridization for mRNA levels. The samples were randomized between the two procedures to overrule any lateralization effects.

\section{ELISA FOR MEASUREMENT OF NPY PEPTIDE CONCENTRATION}

The brains were kept frozen until transfer into acid for extraction of the NPY peptide. The amygdala and prefrontal cortex were dissected from cryostat-sliced sections using bregma -2.12 to -3.6 (amygdala) and 3.20 to 2.20 (PFC) as stereotaxic coordinates (Paxinos and Watson, 1998). Dissected tissue was homogenized in 200-300 $\mu \mathrm{l}$ of $0.2 \mathrm{M} \mathrm{HCl}$. The homogenates were boiled for $5 \mathrm{~min}$ and cooled on ice. Ten microliter aliquots were removed for later analysis of total protein concentrations. Remaining supernatants were then lyophilized overnight in a speed vac to ensure complete drying. Dried extracts were stored at $-80^{\circ} \mathrm{C}$ until ELISA assay.

Frozen samples were re-constituted with ELISA buffer and used for NPY ELISA (Peninsula Laboratories, San Carlos, CA, USA) as described previously (Sah et al., 2009). Homogenate volumes for ELISA were optimized in preliminary runs for each region such that OD readings were obtained within the linear section of the NPY standard curve. Peptide concentration was determined from plotting optical density of unknown samples against a 10 point standard curve for NPY. Total protein was determined by Bradford protein assay. Data was calculated for nanogram NPY per mg protein. Samples from Control and CVS exposed animals were tested for post-CVS early and delayed recovery.

\section{IN SITU HYBRIDIZATION}

Brain samples were coronally sectioned at $14 \mu \mathrm{m}$ on a Leica 3050 cryostat, mounted on Fisherbrand Superfrost-Plus-charged glass slides (Hampton, $\mathrm{NH}, \mathrm{USA}$ ), and stored at $-20^{\circ} \mathrm{C}$ until further analysis. Prior to hybridization, sections were thawed to room temperature and fixed for $15 \mathrm{~min}$ in $4 \%$ paraformaldehyde. Sections were then rinsed $2 \times 5 \mathrm{~min}$ in $5 \mathrm{mM}$ DEPC-treated potassium phosphate buffered saline (KPBS), $2 \times 5$ min in PBS containing $0.2 \%$ glycine, followed by $2 \times 5 \mathrm{~min}$ in KPBS. Sections were acetylated for $10 \mathrm{~min}$ in triethanolamine $(0.1 \mathrm{M}, \mathrm{pH} 8.0)$, containing $0.25 \%$ acetic anhydride, rinsed twice in SSC buffer $(0.25 \mathrm{M}$ sodium chloride, 0.015 sodium citrate, $\mathrm{pH}$ 7.2) for $5 \mathrm{~min}$, followed by dehydration in a graded ethanol series. Sections were re-hydrated to $70 \%$ ethanol and then air-dried. Antisense rat NPY riboprobes were generated (complimentary to bp 20-532 of the NPY sequence Accession \#M15880) by in vitro transcription using ${ }^{35}$ S-labeled UTP. Riboprobe ${ }^{35} \mathrm{~S}$ percent incorporation was determined with TCA precipitation. Labeled probes were added to a hybridization buffer containing 50\% formamide, $20 \mathrm{mM}$ Tris-HCl, pH 7.5, $1 \mathrm{mM}$ EDTA, $335 \mathrm{mM} \mathrm{NaCl}, 1 \times$ Denhardt's solution, $200 \mu \mathrm{g} / \mathrm{ml}$ fish sperm DNA, $150 \mu \mathrm{g} / \mathrm{ml}$ yeast transfer RNA, $20 \mathrm{mM}$ dithiothreitol, and $10 \%$ dextran sulfate. Probes were denatured for $15 \mathrm{~min}$ at $65^{\circ} \mathrm{C}$ and $50 \mu \mathrm{l}\left(1 \times 10^{6} \mathrm{cpm}\right)$ of diluted probe applied to each slide. Slides were coverslipped, placed in moistened chambers, and incubated overnight at $55^{\circ} \mathrm{C}$. After hybridization, coverslips were removed in $0.2 \times \mathrm{SSC}$, and rinsed in fresh $0.2 \times \mathrm{SSC}$ for $10 \mathrm{~min}$. Sections were then treated with RNase A $(50 \mu \mathrm{g} / \mathrm{ml})$ for $30 \mathrm{~min}$ at $37^{\circ} \mathrm{C}$, and transferred to fresh $2 \times \mathrm{SSC}$ and then rinsed three times in $0.2 \times$ SSC $(10 \mathrm{~min} /$ wash $)$, followed by a $1-\mathrm{h}$ wash in $0.2 \times \mathrm{SSC}$ at $65^{\circ} \mathrm{C}$. Finally, sections were dehydrated in a graded ethanol series, dried at room temperature, and exposed for 4-6 days to Kodak BioMAX film (Eastman Kodak, Rochester, NY, USA).

\section{IMAGE ANALYSIS}

Film images of brain sections were captured by digital camera. Semi-quantitative microdensitometry analysis for autoradiograph images was performed using Scion Image (Alpha 4.0.3.2; Scion, Frederick, MD, USA) software. Brain regions were identified using the Paxinos and Watson rat brain atlas. Each identified region of interest was analyzed by subtracting the non-hybridized tissue (background) from the hybridized signal within the same brain section, and data were expressed as corrected gray level (CGL). Multiple brain sections were analyzed per region per animal. Average CGL values were calculated in series for the amygdala and prefrontal cortex. ${ }^{14} \mathrm{C}$ standards were developed with each film and analyzed for CGL to confirm that all measured gray levels were within the linear range of the film.

\section{STATISTICAL ANALYSIS}

Data for NPY ELISA and in situ hybridization for each region was analyzed by unpaired $t$-test for the early and delayed recovery time-point using stress as the variable. Data is expressed as mean \pm standard error of the mean (SEM). Criterion for statistical significance was $p<0.05$. 


\section{RESULTS}

To investigate the regulation of NPY mRNA and peptide in the same animals, brains were bisected in the midline. As a predicted stress resilience factor, it was hypothesized that NPY would be regulated in the amygdala and PFC following traumatic stress, and that these alterations may persist into later recovery. Therefore tissue was collected at timepoints early and later in recovery as depicted in Figure 1A. Consistent with this hypothesis, NPY content in the amygdala showed a significant reduction (38.4\%) at the delayed recovery time-point in the amygdala (Figure 1B). Unpaired $t$-test with stress as the variable revealed significant depletion at this recovery point $(t=2.258 ; p<0.05)$. There was a reduction NPY content at the early time-point (32.2\%), but that did not reach statistical significance. In contrast to the amygdala, NPY peptide concentration in the PFC was significantly upregulated (128.3\%) at delayed recovery $(t=2.761 ; p<0.05$ by unpaired $t$-test), while no changes were noted at early recovery (Figure 1B). To reveal whether alterations in NPY peptide were accompanied by changes in NPY synthesis within the region, NPY mRNA expression was measured in contralateral sections from the same animals (Figure 2). No significant changes in NPY mRNA density were observed at the early recovery time point in the amygdala or the PFC. However, the change in PFC NPY at the 7-day delayed recovery time-point approached statistical significance $(p=0.09)$.

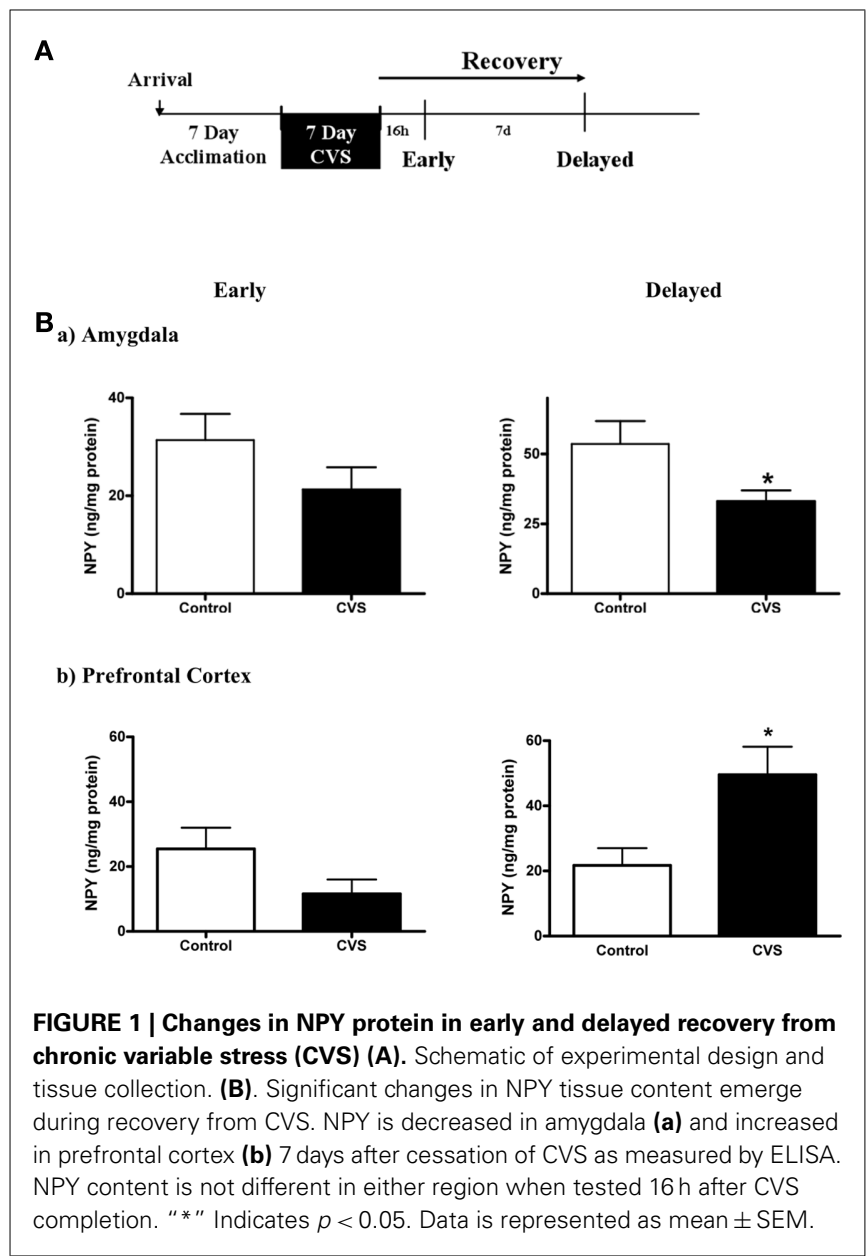

\section{DISCUSSION}

Investigating neural factors associated with recovery and resilience constitutes an important scientific priority for developing treatments for stress-induced disorders, especially PTSD. Here we report that exposure to chronic intermittent stress in an unpredictable fashion can induce long-term alterations in the putative resiliency factor NPY, in limbic brain areas that regulate behavioral, physiological, and cognitive effects of stress and trauma. There are two main findings of our study: first, that significant NPY dysregulation was noted well into the recovery period when restoration and normalization would be expected, and in some cases (PFC) NPY dysregulation appears to be emergent over the recovery period. Second, the amygdala and PFC elicit differential NPY responses to chronic stress that may be caused by different mechanisms. Importantly, dysregulation of NPY is temporally coincident with the expression of enhanced fear recall and emotional arousal that we previously reported in this model (McGuire et al., 2010).

The trajectory of NPY regulation following stress was investigated in the amygdala and PFC based on (a) their well established role in regulation of stress homeostasis and relevance in stress-induced disorders such as PTSD (Shin et al., 2004;
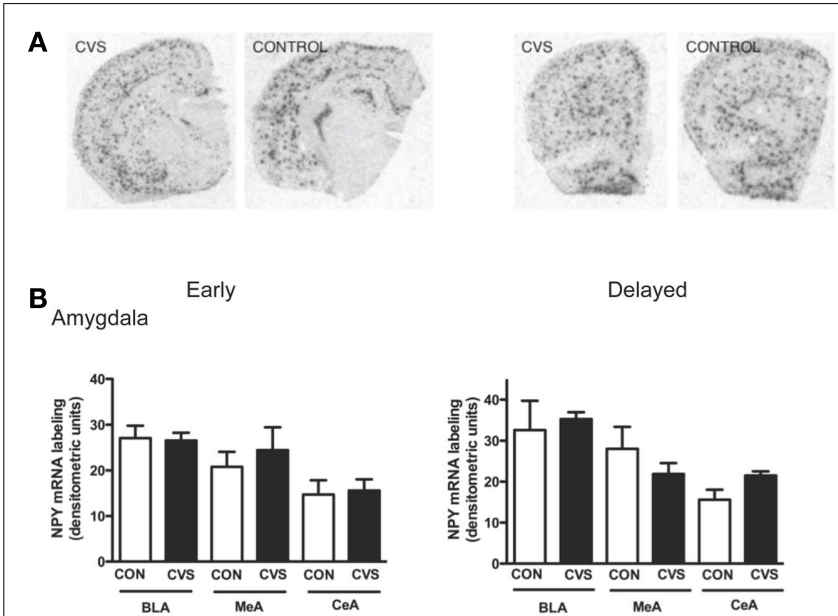

C

PFC
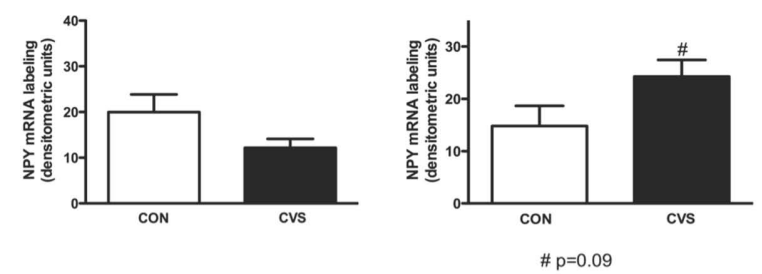

FIGURE 2 | In situ hybridization for NPY mRNA in amygdala and prefrontal cortex during recovery from CVS. (A). Representative images of NPY in situ hybridization from control and CVS animals. (B). Levels of NPY mRNA did not differ between CVS and control brains in basolateral, medial, or central amygdala in either early or delayed recovery. (C). NPY mRNA in the prefrontal cortex did not differ between control and CVS animals in early and delayed recovery. However there was a trend toward increase in NPY mRNA in later recovery when NPY peptide was also increased. "\#" Indicates $p=0.09$. Data is represented as mean \pm SEM. 
Eaton et al., 2007), (b) a defined role of NPY in the control of excitability and pro-stress transmitters in these regions (Bacci et al., 2002; Chung and Moore, 2009; Giesbrecht et al., 2010), and (c) preliminary experiments revealing the absence of persistent CVS-induced regulation of NPY content in other limbic regions such as the hippocampus and hypothalamus (data not shown).

Decreased NPY concentration in the amygdala was observed at delayed post-stress recovery, accompanied by no changes in NPY mRNA synthesis. Since intra-amygdalar NPY mRNA remained unaffected by CVS, reduced NPY peptide content may be a potential outcome of reduced transport via afferent projections to the amygdala. NPY innervation from extra-amygdalar sources has been proposed, although the exact source of afferent inputs are not yet identified (Leitermann et al., 2009; Rostkowski et al., 2009). Reduction of NPY peptide content in the absence of reduced synthesis could also be due to an increase in proteolytic degradation. Previous studies have reported that NPY effects in the CNS are modulated by dipeptidyl peptidase IV. DPPIV-like enzymatic activity is responsible for the cleavage of NPY (Karl et al., 2003). A previous study reported increased NPY mRNA and protein in the amygdala following repeated restraint stress for 910 day (Thorsell et al., 1999). This increase was described as an adaptive functional response that coincided with the absence of behavioral and neuroendocrine deficits that were evident after acute restraint episode. It is possible that paradigms supporting habituation may produce enhanced NPY expression in the amygdala and possibly NPY function. On the other hand, CVS paradigms favor sensitized responses without habituation. This is supported by the delayed expression of sensitized emotional and neuroendocrine responses evoked by CVS in our paradigm (McGuire et al., 2010). Other studies have reported increased NPY concentrations and NPY-immunoreactive fibers in the amygdala 7 day following single prolonged stress exposure (Cui et al., 2008) and elevated NPY mRNA at 2 weeks following single session of multiple footshocks (de Lange et al., 2008). Thus, it is possible that engagement of the putatively "pro-adaptive" NPY system is dependent on stressor modality, duration, and intensity.

We also observed significant increases in NPY peptide and trend toward increase in mRNA expression in the prefrontal cortex at 7 day post-CVS cessation. Impact of chronic stress on the expression of NPY in the PFC has not been investigated previously. Interestingly, modulation of stress on NPY content in the PFC was in the opposite direction as observed in the amygdala. While the exact mechanism for this differential regulation is unclear, we also observed a modest increase in NPY mRNA expression at the same time-point suggesting that increased NPY synthesis may contribute to this effect. Acute stress-induced decrease in cortical NPY mRNA has been reported earlier, however this normalized at $10 \mathrm{~h}$ post-stress (Thorsell et al., 1998). The delayed up-regulation of NPY thus appears to be a result of long-term plasticity within the PFC. Exposure to chronic stress has been shown to induce structural and functional plasticity in this area (Goldwater et al., 2009). These long-term neuroplastic alterations may be accompanied by altered synthesis and content of transmitter systems such as NPY.

\section{IMPLICATIONS OF CVS-EVOKED NPY DYSREGULATION}

In recent years, a prominent role of neuropeptides such as NPY in integrating stress and emotion has emerged (Sajdyk et al., 2004; Alldredge, 2010). Using genetic, behavioral, electrophysiological, and pharmacological approaches, previous studies have determined that NPY in the amygdala promotes successful adaptation to the acute and cumulative effects of stress, anxiolysis, and attenuation of fear (Sajdyk et al., 2008; Fendt et al., 2009; Giesbrecht et al., 2010; Tasan et al., 2010). Persistent reductions in chronic stress evoked NPY in this region would therefore compromise both resiliency to stress as well as induce potentiated fear responses. Exposure to CVS gives rise to exaggerated fear responses and recall following 1 week of recovery (McGuire et al., 2010). These effects are evident at a time when compromised NPY may promote increased excitatory tone in the amygdala leading to sensitized fear responses.

The physiological consequences of NPY expression in the PFC are less well understood. Classification of NPY-expressing cells in the PFC reveals a diverse population of interneurons that are exclusively GABAergic (Karagiannis et al., 2009). NPY elicits a long lasting decrease in evoked excitatory postsynaptic currents through calcium-dependent increase in GABAergic signaling as well as a delayed long lasting increase in inhibitory postsynaptic current (Bacci et al., 2002). Each of these NPY actions would decrease excitability in cortical circuits and output. Significant decrements in synaptic function and neural activity have been reported in the PFC by chronic stress (Wilbur et al., 2011). Increased NPY expression in prefrontal circuits may induce persistent inhibition and reduced excitability leading to dampened PFC output. Given the relevance of PFC in modulating behavioral and neuroendocrine consequences of stress, reduced PFC activity is expected to result in emotional arousal as well sensitization of the hypothalamic pituitary adrenal axis (HPA) responses (Radley et al., 2009; Sotres-Bayon and Quirk, 2010). In agreement with this, we have observed exaggerated fear responses, as well as sensitized HPA responses at the delayed recovery time-point post-CVS (McGuire et al., 2010).

The CVS-recovery paradigm was developed by our group to model chronic traumatization insults and posttraumatic-like outcomes. As described before, this paradigm produces selective effects related to fear memory reinstatement as well as fearful arousal while no significant effects on anxiety are observed (McGuire et al., 2010). NPY in the amygdala has been reported to regulate fear-associated behaviors in several paradigms (Heilig et al., 1992; Britton et al., 2000; Gutman et al., 2008; Fendt et al., 2009) Since NPY has been reported to counteract and contain the effects of stress mediators like CRH (Sajdyk et al., 2004; Giesbrecht et al., 2010) in limbic regions such as the amygdala, it is likely to be released during acute stress responses. However, long-term exposure to stress may dysregulate the NPY system, resulting in reduced inhibition of pro-stress transmitters, and vulnerability to the effects of stress. Although we did not measure $\mathrm{CRH}$ or NE in our current studies, others have reported an upregulation of amygdalar CRH expression following chronic stress (Gray et al., 2010; Wang et al., 2010). Chronic stress induces lasting changes in catecholaminergic neuron structure, and function, particularly in the forebrain (Goldstein et al., 1996; Miner et al., 
2006; Aborelius and Eklund, 2007; Goldwater et al., 2009; Lee et al., 2011), Additionally, increased tonic expression of CRH and NE is associated with a reduced threshold for arousal (van Gaalen et al., 2002; Dierssen et al., 2006). Persistent reduction in amygdalar NPY in the face of enhanced CRH and NE tone will promote exaggerated fear and arousal-associated behaviors that were reported in this model by our group. Likewise, control of excitatory versus inhibitory balance in the cortical output by NPY would be impacted by derangements in NPY that emerge and persist well after stress cessation.

By comparing early and delayed expression of NPY message and protein it is evident that regional disparity exists in how NPY responds to chronic stress. While early decrements in amygdalar NPY are exacerbated with recovery (suggesting depletion), there might exist delayed neuroadaptive changes in the PFC. It is

\section{REFERENCES}

Alldredge, B. (2010). Pathogenic involvement of neuropeptides in anxiety and depression. Neuropeptides 44, 215-224.

Arborelius, L., and Eklund, M. B. (2007). Both long and brief maternal separation produces persistent changes in tissue levels of brain monoamines in middle-aged female rats. Neuroscience $145,738-750$.

Bacci, A., Huguenard, J. R., and Prince, D. A. (2002). Differential modulation of synaptic transmission by neuropeptide $\mathrm{Y}$ in rat neocortical neurons. Proc. Natl. Acad. Sci. U.S.A. 99, 17125-17131.

Britton, K. T., Akwa, Y., Spina, M. G., and Koob, G. K. (2000). Neuropeptide Y blocks anxiogenic-like behavioral action of corticotrophin-releasing factor in an operant conflict test and elevated plus maze. Peptides 21, 37-44.

Chung, L., and Moore, S. D. (2009). Neuropeptides modulate compound postsynaptic potentials in basolateral amygdala. Neuroscience 164, 1389-1397.

Cui, H., Sakamoto, H., Higashi, S., and Kawata, M. (2008). Effects of singleprolonged stress on neurons and their afferent inputs in the amygdala. Neuroscience 152, 703-712.

de Lange, R. P. J., Wiegant, V. M., and Stam, R. (2008). Altered neuropeptide $\mathrm{Y}$ and neurokinin messenger RNA expression and receptor binding in stress-sensitised rats. Brain Res. 1212, 35-47.

Dierssen, M., Gratacos, M., Sahun, I., Martin, M., Gallego, X., AmadorArjona, A., Martinez de Lagran, M., Murtra, P., Marti, E., Pulana, M. A., Ferrer, I., Dalfo, E., Martinez-Cue, C., Florez, J., Torres-Peraza, J. F., Alberch, J., Maldonado, R., Fillat, C., and Estivill, X. (2006). Transgenic mice over-expressing the full-length neurotrophin receptor TrkC exhibit increased catecholaminergic neuron density in specific brain areas and increased anxiety-like behavior and panic reaction. Neurobiol. Dis. 24, 403-418.

Eaton, K., Sallee, F. R., and Sah, R. (2007). Relevance of neuropeptide $Y$ (NPY) in psychiatry. Curr. Top. Med. Chem. 7, 1645-1659.

Fendt, M., Burki, H., Imobersteg, S., Lingenhohl, K., Mcallister, K. H., Orain, D., Uzunov, D. P., and Chaperon, F. (2009). Fear-reducing effects of intra-amydala neuropeptide $\mathrm{Y}$ infusion in animal models of conditioned fear: an NPY Y1 receptor independent effect. Psychopharmacology (Berl.) 206, 291-301.

Fendt, M., and Fanselow, M. S. (1999). The neuroanatomical and neurochemical basis of conditioned fear. Neurosci. Biobehav. Rev. 23, 743-760. Giesbrecht, C. J., Mackay, J. P., Silviera, H. P., Urban, J. H., and Colmers, W. F. (2010). Countervailing modulation of Ih by neuropeptide $\mathrm{Y}$ and corticotrophin-releasing factor in basolateral amygdala as a possible mechanism for their effects on stress-related behaviors. J. Neurosci. 30, 16970-1679782.

Goldstein, L. E., Rasmusson, A. M., Bunney, B. S., and Roth, R. H. (1996). Role of the amygdala in the coordination of behavioral, neuroendocrine, and prefrontal cortical monoamine responses to psychological stress in the rat. J. Neurosci. 16, 4787-4798.

Goldwater, D. S., Pavlides, C., Hunter, R. G., Bloss, E. B., Hof, P. R., Mcewen, B. S., and Morrison, J. H. (2009). Structural and functional alterations to the rat medial prefrontal cortex following chronic restraint stress and recovery. Neuroscience 164, 798-808. Gray, M., Bingham, B., and Viau, V. (2010). A comparison of two

interesting to note that even though these changes are in opposite directions the net outcome may result in enhanced emotional reactivity and sensitized neuroendocrine responses. Another implication of the current study is that dysregulation of limbic NPY may lead to increased vulnerability to subsequent stress or reduced resilience.

In conclusion, persistent dysregulation of NPY, that exists well after cessation of repeated stress may lead to impaired emotional homeostasis and confer vulnerability to subsequent trauma given the stress buffering role of NPY.

\section{ACKNOWLEDGMENTS}

The authors gratefully acknowledge Amanda Jones, Sripana Ghosal, and Ben Packard for their assistance. This work was supported by NIH grant MH083213 (Renu Sah).

repeated restraint stress paradigms on hypothalamic-pituitary-adrenal axis habituation, gonadal status and central neuropeptide expression in adult male rats. J. Neuroendocrinol. 22, 92-101.

Gutman, A. R., Yang, Y., Ressler, K. J., and Davis, M. (2008). The role of neuropeptide $\mathrm{Y}$ in the expression and extinction of fear-potentiated startle. J. Neurosci. 28, 12682-12690.

Heilig, M. (2004). The NPY system in stress, anxiety and depression. $\mathrm{Neu}$ ropeptides 38, 213-224.

Heilig, M., Mckleod, S., Koob, G. K., and Britton, K. T. (1992). Anxiolytic effect of neuropeptide Y (NPY), but not other peptides in an operant confilct test. Regul. Pept. 41, 61-69.

Karagiannis, A., Gallopin, T., David, C. Battaglia, D., Geoffroy, H., Rossier, J., Hillman, E. M; Staiger, J. F., and Cauli, B. (2009). Classification of NPY-expressing neocortical interneurons. J. Neurosci. 29, 3642-3659.

Karl, T., Hoffmann, T., Pabst, R., and Von Horsten, S. (2003). Behavioral effects of neuropeptide $\mathrm{Y}$ in F344 rat substrains with a reduced dipeptidyl-peptidase IV activity. Pharmacol. Biochem. Behav. 75, 869-879.

Lee, Y. A., Poirier, P., Otani, S., and Goto, Y. (2011). Dorsal-ventral distinction of chronic stress-induced electrophysiological alterations in the rat medial prefrontal cortex. Neuroscience 183, 108-120.

Leitermann, R. J., De Joseph, M. R., and Urban, J. H. (2009). “Assessment of extrinsic sources of neuropeptide $\mathrm{Y}$ in the basolateral amygdaloid complex in the rat," in Poster Presentation, Program number 573.18, Society for Neuroscience 2009 Annual meeting, Chicago IL. [Online].

Liberzon, I., and Sripada, C. S. (2008). The functional neuroanatomy of
PTSD: a critical review. Prog. Brain Res. 167, 151-169.

McGuire, J. L., Herman, J. P., Horn, P. S., Sallee, F. R., and Sah, R. (2010). Enhanced fear recall and emotional arousal in rats recovering from chronic variable stress. Physiol. Behav. 101, 474-482.

Miner, L. H., Jedema, H. P., Moore, F. W., Blakely, R. D., Grace, A. A., and Sesack, S. R. (2006). Chronic stress increases the plasmalemmal distribution of the norepinephrine transporter and the coexpression of tyrosine hydroxylase in norepinephrine axons in the prefrontal cortex. J. Neurosci. 26, 1571-1578.

Morgan, C. A. III, Rasmusson, A. M., Winters, B., Hauger, R. L., Morgan, J., Hazlett, G., and Southwick, S. M. (2003). Trauma exposure rather than posttraumatic stress disorder is associated with reduced baseline plasma neuropeptide-Y levels. Biol. Psychiatry 54, 1087-1091.

Paxinos, G., and Watson, C. (1998). The Rat Brain in Stereotaxic Coordinates. New York, NY: Academic Press.

Primeaux, S. D., Wilson, S. P., Cusick, M. C., York, D. A., and Wilson, M. A. (2005). Effects of altered amygdalar neuropeptide Y expression on anxiety-related behaviors. Neuropsychopharmacology 30 , 1589-1597.

Radley, J. J., Gosselink, K. L., and Sawchenko, P. E. (2009). A discrete GABAergic relay mediates medial prefrontal cortical inhibition of the neuroendocrine stress response. J. Neurosci. 29, 7330-7340.

Rostkowski, A. B., Teppen, T. L., Peterson, D. A., and Urban, J. H. (2009). Cell-specific expression of neuropeptide Y Y1 receptor immunoreactivity in the rat basolateral amygdala. J. Comp. Neurol. 517, 166-176. 
Sah, R., Ekhator, N. N., Strawn, J. R., Sallee, F. R., Baker, D. G., Horn, P. S., and Geracioti, T. D. (2009). Low cerebrospinal fluid neuropeptide $\mathrm{Y}$ concentrations in posttraumatic stress disorder. Biol. Psychiatry 66, 705-707.

Sajdyk, T. J., Johnson, P. L., Leitermann, R. J., Fitz, S. D., Deitrich, A., Morin, M., Gehlert, D. R., Urban, J. H., and Shekhar, A. (2008). Neuropeptide Y in the amygdala induces long-term resilience to stress-induced reductions in social responses but not hypothalamic-adrenal-pituitary axis activity or hyperthermia. J. Neurosci. 28, 893.

Sajdyk, T. J., Shekhar, A., and Gehlert, D. R. (2004). Interactions between NPY and CRF in the amygdala to regulate emotionality. Neuropeptides 28 , 225-234.

Shin, L. M., Orr, S. P., Carson, M. A., Rauch, S. L., Macklin, M. L., Lasko, N. B., Peters, P. M., Metzger, L. J., Dougherty, D. D., Cannistraro, P. A., Alpert, N. M., and Fischman, A. J. (2004). Regional cerebral blood flow in the amygdala and prefrontal cortex during traumatic imagery in male and female Vietnam veterans with PTSD. Arch. Gen. Psychiatry 61, 168-176.

Shin, L. M., Rausch, S. L., and Pitman, R. K. (2006). Amygdala, medial prefrontal cortex and hippocampal function in PTSD. Ann. N. Y. Acad. Sci. 1071, 67-79.

Sommer, W. H., Lidstrom, J., Sun, H., Passer, D., Eskay, R., Parker, S. C., Witt, S. H., Zimmerman, U. S., Nieratschker, V., Reitschel, M., Margulies, E. H., Palkovitz, M., Laught, M., and Heilig, M. (2010). Human NPY promoter variation rs16147: $\mathrm{T}>\mathrm{C}$ as a moderator of prefrontal NPY gene expression and negative affect. Hum. Mutat. 31, E1594-E1608.

Sotres-Bayon, F., and Quirk, G. J. (2010). Prefrontal control of fear: more than just extinction. Curr. Opin. Neurobiol. 20, 231-235.

Tasan, R. O., Nguyen, N. K., Weger, S., Sartori, S. B., Singewald, N., Heilbronn, R., Herzog, H., and Sperk, G. (2010). The central and basolateral amygdala are critical sites of neuropeptide Y/Y2 receptor-mediated regulation of anxiety and depression. J. Neurosci. 30, 6282-6290.

Thorsell, A., Carlsson, K., Ekman, R., and Heilig, M. (1999). Behavioral and endocrine adaptation, and upregulation of NPY expression in rat amygdala following repeated restraint stress. Neuroreport 10, 3003-3007.

Thorsell, A., Michalkiewicz, M., Dumont, Y., Quirion, R., Caberlotto, L., Rimondini, R., Mathe, A. A., and Heilig, M. (2000). Behavioral insensitivity to restraint stress, absent fear supression of behavior and impaired spatial learning in transgenic rats with hippocampal neuropeptide Y overexpression. Proc. Natl. Acad. Sci. U.S.A. 97, 12852-12857.

Thorsell, A., Svensson, P., Wiklund, L., Sommer, W., Ekman, R., and Heilig, M. (1998). Suppressed neuropeptide $\mathrm{Y}$ (NPY) mRNA in the amygdala following restraint stress. Regul. Pept. 75-76, 247-254.

van Gaalen, M. M., Stenzel-Poore, M. P., Holsboer, F., and Steckler, T. (2002). Effects of transgenic overproduction of $\mathrm{CRH}$ on anxiety-like behavior. Eur. J. Neurosci. 15, 2007-2015.

Wang, S. S., Yan, X. B., Hofmann, M. A., Swaab, D. F., and Zhou, J. N. (2010). Increased expression level of corticotrophin-releasing hormone in the amygdala and in the hypothalamus in rats exposed to chronic unpredictable mild stress. Neurosci. Bull. 26, 297-303.

Wilbur, A. A., Walker, A. G., Southwood, C. J., Farrell, M. R., Lin, G. L., Rebec, G. V., and Wellman, C. L. (2011). Chronic stress alters neural activity in prefrontal cortex during retrieval of extinction. Neuroscience 174, 115-131.

Yehuda, R., Brand, S., and Tang, R. K. (2006). Plasma neuropeptide Y concentrations in combat exposed veterans: relationship to trauma exposure, recovery from PTSD, and coping. Biol. Psychiatry 59, 660-663.
Zhou, A., Zhu, G., Hariri, A. R., Enoch, M. A., Scott, D., Sinha, R., Virkkunen, M., Mash, D. C., Lipsky, R. H., Hu, X. Z., Hodgkinson, C. A., Xu, K., Buzas, B., Yuan, Q., Shen, P. H., Ferrel, R. E., Manuck, S. B., Brown, S. M., Hauger, R. L., Stohler, C. S., Zubieta, J. K., and Golman, D. (2008). Genetic variation in NPY expression affects stress response and emotion. Nature 452, 997-1002.

Conflict of Interest Statement: The authors declare commercial or financial relationships that could be construed as a potential conflict of interest.

Received: 14 April 2011; accepted: 13 August 2011; published online: 15 September 2011.

Citation: McGuire JL, Larke LE, Sallee FR, Herman JP and Sah R (2011) Differential regulation of neuropeptide $Y$ in the amygdala and prefrontal cortex during recovery from chronic variable stress. Front. Behav. Neurosci. 5:54. doi: 10.3389/fnbeh.2011.00054

Copyright (c) 2011 McGuire, Larke, Sallee, Herman and Sah. This is an openaccess article subject to a non-exclusive license between the authors and Frontiers Media SA, which permits use, distribution and reproduction in other forums, provided the original authors and source are credited and other Frontiers conditions are complied with. 